\title{
Pesticide dispersion-advection equation with soil temperature effect
}

\author{
Lourival Costa Paraiba ${ }^{1, *, \dagger}$ and Petronio Pulino ${ }^{2}$ \\ ${ }^{1}$ Embrapa Meio Ambiente, CP 69, 13820-000, Jaguariúna, São Paulo, Brazil \\ ${ }^{2}$ Department of Applied Mathematic, IMECC-UNICAMP, CP 6065, 13083-970, Campinas, São Paulo, Brazil
}

\begin{abstract}
SUMMARY
A dispersion-advection equation, denoted as a DAPESTE model, of one-dimensional evolution to simulate pesticide leaching in soil with a sinusoidal function to describe the daily average soil temperature at different depths is presented. In numerical simulation, the finite element method (FEM) will be used for space semidiscretization and the regressive Eüler method (REM) for time discretization. It will be used as an FEM for dispersion-advection problems in which the advective transport predominates over the dispersive one. Let us suppose that the pesticide diffusivities in the gaseous and aqueous soil phases depend on the soil temperature. In this way, the effective hydrodynamic dispersion coefficient of the dispersion-advection equation will depend on the soil temperature. The pesticide air-water partition coefficient of the Henry law, varying with temperature, will be determined by the Clausius-Clapeyron equation. The van't Hoff equation will be used to determine the temperature dependence of the pesticide soil sorption coefficient. The Arrhenius equation will be used to estimate the effect of the soil temperature on the pesticide degradation rate. These temperature dependence relationships can help comprehend the pesticide behavior in the soil under different scenarios of the soil temperatures, especially in pesticide concentration leaching and its half-life in soil. Copyright (C) 2003 John Wiley \& Sons, Ltd.
\end{abstract}

KEY WORDS: DAPESTE; dispersion; advection; pesticide; temperature; leaching

\section{INTRODUCTION}

The impact of pesticides on groundwater quality has been object of research and public health issues, especially in areas where the groundwater is the main source of drinking water. Owing to the complexity of physical, chemical and biological processes involved in the transport and fate of organic chemical compounds to groundwater, mathematical models are, frequently, used by government agencies and private corporations in ranking levels of groundwater contamination risk (Boesten, 2000). The convection of water flow in the groundwater direction and the effective dispersion water solute in the soil matrix control the transport and destination of pesticide in soil. The hydrodynamic dispersion of soil solution, gaseous diffusion and aqueous diffusion of the pesticide determine the effective dispersion component of the pollutant transport in the soil.

The pesticide sorption characteristic and pesticide half-life in the soil describe the pesticide leaching potential and persistence in soil. However, a uniform first-order decay constant resulting in a continuous exponential decay of a compound added at the surface during its entire time in the vadose

*Correspondence to: Lourival Costa Paraiba, Embrapa Meio Ambiente, CP 69, 13820-000, Jaguariúna, São Paulo, Brazil.

${ }^{\dagger}$ E-mail: lourival@cnpma.embrapa.br 
zone has been frequently assumed (Wagenet and Rao, 1990). This is somewhat unrealistic because soil temperature decreases with depth during daytime in summer, and sorption and microbial rate processes are known to be affected by temperature. The potential groundwater pesticide contamination can differ if the effect of the soil temperature on the pesticide soil degradation rate, water-air partition and the water-soil sorption process are not considered. Thus, we will present a dispersion-advection equation of one-dimensional evolution which simulates the nonionic pesticide leaching in the soil when one considers periodical variation of the average daily soil temperature profile on the gaseous and aqueous diffusion, in the pesticide degradation rate, on the pesticide soil sorption coefficient and on the dimensionless pesticide partition water-air coefficient of Henry law.

The effects of soil temperature on the pesticide degradation and pesticide transport was modeled and observed by Padilla et al. (1988), Reichman et al. (2000a) and Reichman et al. (2000b). Padilla et al. (1988) proposed a dispersion-advection equation type to simulate the pesticide transport, transformation and fate in unsaturated soil, which considers the temperature effect on the pesticide soil degradation rate and pesticide soil sorption coefficient. The dispersion-advection model proposed by Padilla et al. (1988) is constituted by a system of partial differential equations where each partial equation corresponds, respectively, to the heat dispersion-advection equation, the unsaturated soil water flow and the solute dispersion-advection equation. This model was solved numerically by an appropriate finite element method.

The DAPESTE (dispersion-advection of pesticides in the soil based on soil temperature effect) model considers a sinusoidal function expression that describes the annual variation of daily average soil temperature at different depths and a constant pore water velocity in an unsaturated homogeneous soil profile. We have obtained numerical solutions from a DAPESTE model, through the FEM for the semi-discretization of the space variable and the REM for the discretization in the time variable of the model. We have used an appropriate FEM for dispersion-advection problems in which the advective transport predominates over the dispersive one.

The Galerkin method with linear Lagrange and quadratic functions (Rappaz and Picasso, 1998), the Galerkin method with linear Lagrange and bubble functions, which is equivalent to the PetrovGalerkin method type (Johnson, 1987), and streamline upwind Petrov-Galerkin methods (Rappaz and Picasso, 1998) were implemented in the DAPESTE model.

\section{CLASSICAL DISPERSION-ADVECTION EQUATION}

According to Jury et al. (1983), in an unsaturated homogeneous soil profile, if the soil temperature, soil bulk density $\rho\left(\mathrm{kg} \mathrm{m}^{-3}\right)$, volumetric fraction organic carbon content $f_{\text {oc }}$, volumetric fraction air content $\delta$, volumetric fraction water content $\theta$ and apparent degradation rate $\mu\left(\mathrm{d}^{-1}\right)$ are constants, then the aqueous soil solution pesticide concentration $C\left(\mathrm{~g} \mathrm{~m}^{-3}\right)$ is given by the classical dispersion-advection equation,

$$
D_{\mathrm{E}} \frac{\partial^{2} C}{\partial z^{2}}-J_{\mathrm{W}} \frac{\partial C}{\partial z}-R \frac{\partial C}{\partial t}-\mu R C=0
$$

where $C=C(z, t), D_{\mathrm{E}}=D_{\mathrm{LH}}+H D_{\mathrm{G}}+D_{\mathrm{L}}$ is the effective dispersion coefficient, $J_{\mathrm{W}}=V \theta\left(\mathrm{m} \mathrm{d}^{-1}\right)$ is the water flux by advection, where $V$ is the pore water velocity by advection, $R=\rho K_{\mathrm{D}}+\theta+\delta H$ is the liquid phase partition coefficient, $t$ (day) is the time and $z(\mathrm{~m})$ is the soil depth. The effective dispersion coefficient includes the hydrodynamic dispersion $D_{\mathrm{LH}}\left(\mathrm{m}^{2} \mathrm{~d}^{-1}\right)$, air-water pesticide 
partition coefficient (dimensionless Henry constant) $H$, pesticide gaseous diffusion $D_{\mathrm{G}}\left(\mathrm{m}^{2} \mathrm{~d}^{-1}\right)$ and pesticide aqueous diffusion $D_{\mathrm{L}}\left(\mathrm{m}^{2} \mathrm{~d}^{-1}\right)$. Moreover, the factor $R$ includes the water-soil pesticide sorption coefficient $K_{\mathrm{d}}\left(\mathrm{m}^{3} \mathrm{~kg}^{-1}\right)$.

Generally, the partition coefficient $K_{\mathrm{d}}$ is linear and directly related to the pesticide partition organic carbon coefficient $K_{\mathrm{oc}}\left(\mathrm{m}^{3} \mathrm{~kg}^{-1}\right)$ and the volumetric fraction of the soil organic carbon $f_{\mathrm{oc}}$ by the expression

$$
K_{\mathrm{d}}=K_{\mathrm{oc}} f_{\mathrm{oc}}
$$

Bear (1972), Bigger and Nielsen (1976) and Anderson (1979) have observed that the hydrodynamic dispersion coefficient depends on the distance traveled by the soil solution and on the pore water velocity. Klotz et al. (1980), based on field and laboratory experiments, using soils of different physical properties, suggested that the empiric relation given by

$$
D_{\mathrm{LH}}=\lambda V^{x}
$$

can be used to estimate the hydrodynamic dispersion coefficient, where $\lambda(\mathrm{m})$ is the dispersion length. In this relationship the dimensionless $x(1.0 \leq x \leq 1.2)$ parameter represents the correlation between soil type and longitudinal dispersion parameter $\lambda$. Subjected to some special assumptions, Jury et al. (1991) have suggested that Equation (3) can be expressed by $D_{\mathrm{LH}}=\lambda V$. The pore water velocity is estimated by the relation $V=J_{\mathrm{W}} / \theta$, where $J_{\mathrm{W}}\left(\mathrm{m} \mathrm{d}^{-1}\right)$ is the water flux by advection. In our numerical simulations, we will adopt this last relation suggested by Jury et al. (1991).

The gaseous pesticide diffusion coefficient or the diffusive flux in the soil gaseous phase is estimated by the expression

$$
D_{\mathrm{G}}=\xi(\delta) D_{\mathrm{cg}}
$$

where $\xi(\delta)=\delta^{10 / 3} / \phi^{2}$ is an empirical numerical coefficient which describes the effect of the soil tortuosity on the pesticide gaseous diffusivity and $\phi$ represents the volumetric soil porosity (Millington, 1959; Millington and Quirk, 1961; Currie, 1965). The parameter $D_{\mathrm{cg}}\left(\mathrm{m}^{2} \mathrm{~d}^{-1}\right)$ is the pesticide diffusivity coefficient in soil air. There are many possible numerical expressions to estimate the diffusivity parameter $D_{\mathrm{cg}}$. A frequently used expression to calculate this diffusivity coefficient is described by the empirical numerical expression given by Lyman et al. (1982),

$$
D_{\mathrm{cg}}=\frac{10^{-3} T^{1.75} \sqrt{M}}{p\left(V_{\mathrm{g}}^{1 / 3}+V_{\mathrm{c}}^{1 / 3}\right)^{2}}
$$

where $T(\mathrm{~K})$ is the absolute temperature, $p(\mathrm{~atm})$ is the atmospheric pressure, $V_{\mathrm{g}}\left(\mathrm{cm}^{3} \mathrm{~mol}^{-1}\right)$ is the air molar volume, $V_{\mathrm{c}}$ is the pesticide molar volume and $M=\left(m_{\mathrm{g}}+m_{\mathrm{c}}\right) / m_{\mathrm{g}} m_{\mathrm{c}}$, with $m_{\mathrm{g}}$ and $m_{\mathrm{c}}$ representing the air molar mass and pesticide molar mass, respectively.

The pesticide aqueous diffusion coefficient in the soil solution or the diffusive flux in the soil liquid phase is estimated by the expression

$$
D_{\mathrm{L}}=\xi(\delta) D_{\mathrm{cw}}
$$

where the parameter $D_{\mathrm{cw}}\left(\mathrm{m}^{2} \mathrm{~d}^{-1}\right)$ is the pesticide diffusivity in water. There are many possible numerical expressions to estimate the diffusivity parameter $D_{\mathrm{cw}}$. In environmental problems, the Wilke-Chang equation (Bird et al., 1960; Weber and DiGiano, 1995) is perhaps the most used 
equation to estimate the diffusivity of a pesticide in soil water. This expression is described by the numeric empirical relationship given by

$$
D_{\mathrm{cw}}=\frac{7.4 \times 10^{-8}\left(\varphi_{\mathrm{W}}^{\circ} m_{\mathrm{W}}\right)^{0.5} T}{\mu_{\mathrm{v}} V_{\mathrm{c}}^{0.6}}
$$

where $\varphi_{\mathrm{W}}^{\circ}$ is a solvent (water) association term (2.6 for the water), $m_{\mathrm{W}}$ is the water molecular mass $\left(18 \mathrm{~g} \mathrm{~mol}^{-1}\right), \mu_{\mathrm{v}}$ is the water viscosity $\left(8.9 \times 10^{-1} \mathrm{cp}\right)$ and $V_{\mathrm{c}}\left(\mathrm{cm}^{3} \mathrm{~mol}^{-1}\right)$ is the pesticide molar volume.

\section{DISPERSION-ADVECTION EQUATION AND SOIL TEMPERATURE EFFECTS: THE DAPESTE MODEL}

We will present modifications and numerical solutions to the classical dispersion-advection Equation (1) when we consider the soil temperature effect on the gaseous and aqueous diffusivities, pesticide soil sorption coefficient, water-air partition coefficient and pesticide soil degradation rate. It is necessary to adopt a sinusoidal function that describes the annual variation of the daily average soil temperature at different depths. Thereby, the following expression was adopted to estimate the absolute soil daily temperature (Campbell, 1985; Jury et al., 1991; Wu and Nofzinger, 1999),

$$
T(z, t)=T_{\mathrm{a}}+\left(A_{0} \exp (-z / \zeta)\right) \sin \left(w t-z / \zeta-\psi_{0}\right)
$$

where $T(z, t)$ is the daily average soil temperature in $z(\mathrm{~m})$ meters of depth and $t(\mathrm{~d})$ days, $T_{\mathrm{a}}(\mathrm{K})$ is the annual mean soil temperature, $A_{0}(\mathrm{~K})$ is the annual amplitude of the surface soil temperature fluctuation, $\zeta(\mathrm{m})$ is the damping depth of annual fluctuation, $\varpi=2 \pi / 365\left(\mathrm{~d}^{-1}\right)$ is the radial frequency, $\psi_{0}=\pi / 2+\varpi t_{0}$ is the phase constant, and $t_{0}$ is the time lag from the arbitrary starting date to the occurrence of the minimum temperature in a year. The damping depth $\zeta$ is a parameter characterizing the attenuation of temperature fluctuation with depth from the soil surface. This parameter can be calculated by $\zeta=\sqrt{2 \kappa / C_{\mathrm{h}} \varpi}$, where $\kappa\left(\mathrm{kJ} \mathrm{m}^{-1} \mathrm{~K}^{-1} \mathrm{~d}^{-1}\right)$ is the thermal conductivity and $C_{\mathrm{h}}$ $\left(\mathrm{kJ} \mathrm{m}^{-3} \mathrm{~K}^{-1}\right)$ is the volumetric heat capacity of the soil (Hillel, 1982; Marshall and Holmes, 1988).

The soil temperature profile, by affecting the soil microbial activity, has a great effect on the pesticide half-life in soil. In a reference soil temperature $T_{\mathrm{r}}(\mathrm{K})$, it is known that the half-life of a pesticide in a soil is given by $t_{1 / 2}^{\mathrm{r}}=\operatorname{Ln}(2.0) / \mu_{\mathrm{r}}$, where $\mu_{\mathrm{r}}\left(\mathrm{d}^{-1}\right)$ is the apparent degradation rate in a reference temperature. Generally, the reference temperature is between 293 and $298 \mathrm{~K}$. Reciprocally, when one knows the pesticide half-life in the soil at reference temperature $T_{\mathrm{r}}$, one can estimate the pesticide degradation rate in a soil with first order kinetic from the expression

$$
\mu_{\mathrm{r}}=\frac{\operatorname{Ln}(2.0)}{t_{1 / 2}^{\mathrm{r}}}
$$

The Arrhenius equation was used to estimate the dependence between the pesticide degradation rate and the soil temperature. This degradation equation rate is given by the expression (Walker, 1987; Keen and Spain, 1992; Veeh et al., 1996; Wu and Nofzinger, 1999)

$$
\mu(\mathrm{T})=\mu_{\mathrm{r}} \exp \left(\frac{E_{\mathrm{a}}}{R}\left(\frac{T-T_{\mathrm{r}}}{T T_{\mathrm{r}}}\right)\right)
$$


where $E_{\mathrm{a}}\left(\mathrm{kJ} \mathrm{mol}^{-1} \mathrm{~K}^{-1}\right)$ is the Arrhenius activation energy for the degradation process, $R=0.008315$ $\mathrm{kJ} \mathrm{mol}^{-1} \mathrm{~K}^{-1}$ is the universal gas constant and $T=T(z, t)$. Based on fundamental thermodynamic principles, the Clausius-Clapeyron equation (Mackay et al., 1986; Sagebiel et al., 1992; Staundinger and Roberts, 1996) was used to estimate the dependence between the dimensionless Henry law coefficient and the soil temperature. This equilibrium equation is given by

$$
H(\mathrm{~T})=H_{\mathrm{r}} \exp \left(\frac{\Delta H_{\mathrm{v}}}{R}\left(\frac{T-T_{\mathrm{r}}}{T T_{\mathrm{r}}}\right)\right)
$$

where $\Delta H_{\mathrm{v}}\left(\mathrm{kJ} \mathrm{mol}^{-1} \mathrm{~K}^{-1}\right)$ is the pesticide volatilization enthalpy and $H_{\mathrm{r}}$ is the air-water pesticide partition coefficient in a reference temperature. The dimensionless Henry coefficient in a reference temperature $H_{\mathrm{r}}$ can be estimated by

$$
H_{\mathrm{r}}=\frac{P_{\mathrm{v}} P_{\mathrm{w}}}{S R T_{\mathrm{r}}}
$$

where $P_{\mathrm{v}}(\mathrm{Pa}), P_{\mathrm{w}}\left(\mathrm{g} \mathrm{mol}^{-1}\right)$ and $S\left(\mathrm{~g} \mathrm{~m}^{-3}\right)$ are the pesticide saturated vapor pressure, the pesticide molecular mass and the pesticide aqueous solubility, respectively. $H$ being a partition air-water coefficient, it is expected that this parameter shows a significant dependence on the environment temperature. Kanavaugh and Trussel (1980) affirm that the Henry constant increases by a factor of 1.6 for each $10 \mathrm{~K}$ rise in the average environmental temperature. For a volatile pesticide, when the environmental temperature increases by $10 \mathrm{~K}$, a triple increase of the Henry constant is produced. The pesticide soil sorption coefficient between the aqueous phase and the solid matter of the soil $K_{\mathrm{d}}$, when we assume a linear and instantaneous sorption process, can be estimated from the van't Hoff equation (Padilla et al., 1988; Fruhstorfer et al., 1993; Goss and Schwarzenbach, 1999), which is given by

$$
K_{\mathrm{d}}(T)=K_{\mathrm{d}}^{\mathrm{r}} \exp \left(\frac{\Delta H_{\mathrm{a}}}{R}\left(\frac{T_{\mathrm{c}}-T}{T T_{\mathrm{r}}}\right)\right)
$$

where $\Delta H_{\mathrm{a}}\left(\mathrm{kJ} \mathrm{mol}^{-1} \mathrm{~K}^{-1}\right)$ is the pesticide heat of sorption reaction and $K_{\mathrm{d}}^{\mathrm{r}}$ is the pesticide sorption coefficient in a reference temperature. The pesticide soil sorption depends on the energy transference during the pesticide sorption process. For a large number of non-ionic organic compounds an opposite relation of dependence between the sorption coefficient and the soil temperature has been observed (Chiou et al., 1979; Szecsody and Roger, 1991). However, for some organic chemical compounds, as it was experimentally observed by He et al. (1995), sorption of fluoranthene in soil solid matters increases with the rise in soil temperature. The soil sorption coefficient can be affected by two different forms depending on whether the $\Delta H_{\mathrm{a}}$ is positive or negative. For an exothermic reaction, heat of sorption $\left(\Delta H_{\mathrm{a}}<0\right)$, the sorption coefficient $K_{\mathrm{d}}$ decreases with the increase in soil temperature. Reciprocally, for an endothermic reaction, heat of sorption $\left(\Delta H_{\mathrm{a}}>0\right)$, the sorption coefficient $K_{\mathrm{d}}$ increases with the increase in soil temperature. The use of the van't Hoff equation to estimate soil temperature effects on pesticide sorption coefficient is only applied for linear and instantaneous sorption processes. Thereby, assuming these particular conditions, Equation (13) can be applied to determine $K_{\mathrm{d}}$ values in different soil temperatures and estimate the pesticide soil concentration. However, the variability of the $\Delta H_{\mathrm{a}}$ values, which are the consequence of each particular sorption system condition, such as the soil mineral and organic matter contents, can lead to significant uncertainties in the predictions of $K_{\mathrm{d}}$ values (Padilla et al., 1988). 
When $\Delta H_{\mathrm{v}}$ and $\Delta H_{\mathrm{a}}$ are not known or when they are not available in the literature, we can use the Goss and Schwarzenbach (1999) relationship to estimate these values. Such empirical relations to estimate $\Delta H_{\mathrm{v}}$ and $\Delta H_{\mathrm{a}}$ values are given by

$$
\begin{gathered}
\Delta H_{\mathrm{v}}=-3.82 \operatorname{Ln}\left(P_{\mathrm{v}}^{293}\right)+70.0 \\
\Delta H_{\mathrm{a}}=-4.17 \operatorname{Ln}\left(\frac{K_{\mathrm{d}}^{293}}{1.0 \times 10^{3} \overline{S S}}\right)-88.1
\end{gathered}
$$

where $P_{\mathrm{v}}^{293}(\mathrm{~Pa})$ is the saturated vapor pressure in the reference temperature $\left(T_{\mathrm{r}}=20^{\circ} \mathrm{C}\right), K_{\mathrm{d}}^{293}$ $\left(\mathrm{m}^{3} \mathrm{~kg}^{-1}\right)$ is the sorption coefficient in the same reference temperature and $\overline{S S}\left(\mathrm{~m}^{2} \mathrm{~g}^{-1}\right)$ is the average specific surface of the soil. The specific surface is calculated as follows (Vighi and Di Guardo, 1995):

$$
S S=100.0\left(100.0 f_{\mathrm{oc}}+2.0 f_{\mathrm{cl}}+0.4 f_{\mathrm{st}}+0.005 f_{\mathrm{sd}}\right)
$$

where $f_{\mathrm{oc}}$ is the soil carbon volumetric fraction, $f_{\mathrm{cl}}$ is the soil clay volumetric fraction, $f_{\mathrm{st}}$ is the soil silt volumetric fraction and $f_{\text {sd }}$ is the soil sand volumetric fraction.

Mackay et al. (1986) applied a factor of $0.084\left(\mathrm{~kJ} \mathrm{~mol}^{-1} \mathrm{~K}^{-1}\right)$ to Trouton's rule (1884) to estimate $\Delta H_{\mathrm{v}}$ for an organic compound from its normal boiling point (Bacci, 1994). This rule is given by $\Delta H_{\mathrm{v}}=0.084 b p$, where $b p$ is the absolute temperature of the organic compound normal boiling point. In our numeric simulation the Goss and Schwarzenbach (1999) relations was used to estimate $\Delta H_{\mathrm{v}}$ and $\Delta H_{\mathrm{a}}$.

Supposing that the air, water and organic carbon volumetric contents of the soil are constant and having adopted Equation (8) to estimate the annual variation of daily average soil temperature at different depths, the hydrodynamic dispersion, Equation (3), the gaseous and aqueous diffusion coefficients of the pesticide in the soil, Equations (4) and (6), temperature degradation rate, Equation (10), temperature air-water partition coefficient, Equation (11), and temperature pesticide sorption coefficient, Equation (13), it is possible to modify Equation (1) in such a way that soil temperature can be considered in the dynamics of dispersion and advection of pesticide in soil to estimate the pesticide soil concentrations. Thus, we can write Equation (1) as

$$
\frac{\partial}{\partial z}\left(D_{\mathrm{E}}(T) \frac{\partial C(z, t)}{\partial z}\right)-\frac{\partial}{\partial z}\left(J_{\mathrm{E}}(T) C(z, t)\right)-R(T) \frac{\partial C(z, t)}{\partial t}-\mu(T) R(T) C(z, t)=0
$$

where

$$
\begin{array}{r}
D_{\mathrm{E}}=D_{\mathrm{LH}}+D_{\mathrm{G}}(T)+D_{\mathrm{L}}(T) H(T) \\
J_{\mathrm{E}}(T)=-D_{\mathrm{L}}(T) \frac{\partial H(T)}{\partial z}+J_{\mathrm{W}} \\
R(T)=\rho K_{\mathrm{D}}(T)+\theta+\delta H(T)
\end{array}
$$

and $T=T(z, t)$. It is important to observe that the liquid phase partition coefficient $R=R(T)$ depends on soil temperature, because when we include the soil temperature it affects the pesticide sorption coefficient and pesticide air-water partition coefficient. Equation (16) describes the evolution of the pesticide concentration in the soil solution under the soil temperature profile. This expression is the governing equation of the DAPESTE model. 


\subsection{Initial conditions}

The top layer of the soil, which initially contains the pesticide, is considered as part of the soil profile and its existence is incorporated to the initial conditions. The modeled soil profile has a form of $z=0$ up to $z=+\infty$. The initial conditions are then given by

$$
\begin{gathered}
C(z, 0)=\frac{a d}{\varepsilon\left(\rho K_{\mathrm{d}}(z, 0)+\theta+\delta H(z, 0)\right)} \quad 0<z \leq \varepsilon \\
C(z, 0)=0 \quad \varepsilon<z<+\infty
\end{gathered}
$$

where $a d\left(\mathrm{~g} \mathrm{~m}^{-2}\right)$ is the pesticide application dose and $\varepsilon$ is a top layer width of the superficial soil which describes the incorporation of the pesticide applied to the soil. The model given by Equation (16) needs two boundary conditions.

\subsection{Boundary conditions}

In the definition of the upper boundary condition it is assumed that the water added on top of the soil is free from the pesticide and that there is not a concentration gradient in the soil layer of infinite depth. Therefore, the boundary conditions are given by:

$$
\begin{gathered}
J_{\mathrm{E}}(T(0, t)) C(0, t)+D_{\mathrm{E}}(T(0, t)) \frac{\partial C(0, t)}{\partial z}=0 \quad t \geq 0 \\
\frac{\partial C(+\infty, t)}{\partial z}=0 \quad t \geq 0
\end{gathered}
$$

These boundary conditions define the solute flux on the boundary surface and are known as Cauchy conditions. Similar initial and boundary conditions have been suggested also by the works of Lindstrom and Boersma (1971), Jury et al. (1990), Toride et al. (1993) and Freijer et al. (1998) and are well described in Sun (1995). To numerically solve Equation (16) with the initial and boundary conditions given by Equations (17)-(20) means to estimate numerically the pesticide concentration under the stationary soil water flux in a homogeneous soil profile.

\subsection{The soil temperature dependent pesticide half-life}

The pesticide concentration values in the soil aqueous phase, as a result of the numerical solution obtained by the FEM applied to Equation (16) and its respective initial and boundary conditions given by Equations (17)-(20), can be numerically integrated to the whole soil profile to produce a real time function that describes the relative quantity of the pesticide in soil which is useful to estimate the pesticide half-life in soil. Thus, it is possible, for each simulation scenario of the annual variation of daily average soil at different depths, to calculate the temperature dependent pesticide half-life. With these numerical procedures we can estimate the pesticide half-life under the influence of the soil temperature, having as a starting-point the pesticide half-life obtained in a laboratory at a reference temperature, for instance, $293 \mathrm{~K}$. The numerical expression that estimates the pesticide relative quantity, as a function of time, in the whole soil profile is given by

$$
Q(t)=\frac{\varepsilon}{a d} \int_{0}^{l} C\left(z^{\prime}, t\right)\left(\rho K_{\mathrm{d}}\left(T\left(z^{\prime}, t\right)\right)+\theta+\delta H\left(T\left(z^{\prime}, t\right)\right)\right) \mathrm{d} z^{\prime}
$$


where $l$ is the maximum soil depth profile and $t(d)$ is the time. The following relationship is used to express temperature dependence of the pesticide half-life:

$$
\hat{t}_{1 / 2}=Q^{-1}(0.5)
$$

\section{SIMULATION AND NUMERICAL RESULTS}

We have selected the herbicide atrazine to simulate, by a DAPESTE model, the effect of the soil temperature on the leaching and soil degradation of this pesticide. s-Triazine herbicides such as atrazine (2-chloro-4-isopropylamino-6-ethylamino-s-triazine) are the most popular agents for controlling weeds in upland fields. The atrazine is recommended for pre-emergence application in soil for crop plants such as corn, sugar-cane, sorghun, soya, etc. (Esser et al., 1975), and it is the herbicide contaminant most found in groundwater (Hance, 1987). Atrazine can persist for longer than 1 year under dry or cold conditions. Atrazine is moderately to highly mobile in soils with low clay or organic matter content. Because it does not adsorb strongly to soil particles and has a lengthy half-life of 60 to $>100$ days, it has a high potential for groundwater contamination despite its moderate solubility in water (Wauchope et al., 1992). Atrazine is the second most common pesticide found in private wells and in community wells. Trace amounts have been found in drinking water samples and in groundwater samples in a number of states of the U.S.A. (EPA, 1990; Howard, 1989). The breakdown of atrazine in the field is slower under winter than summer conditions in Canada: the half-life of this compound was 1.4 months in the summer and increased to 3 to 4 months in the winter (Frank and Sirons, 1985; Wang, 1999). The effect of temperature on dissipation of atrazine in a Brazilian Gley Humic soil has been studied by Andréa et al. (1997). The environmental impact of herbicide use in the subtropics has been reviewed by Wang (1999).

We have taken a sample of a Quartzous sand Brazilian soil with the characteristics used in our numerical simulation presented in Table 1 . Table 2 presents the necessary physical-chemical characteristics of the pesticide atrazine to estimate the Henry law constant, gaseous and aqueous diffusion in the soil, pesticide sorption coefficient, and apparent degradation rate in the soil. These physicalchemical characteristics were compiled by Hornsby et al. (1996) and are obtained in a laboratory at a temperature of 293 or $298 \mathrm{~K}$. In our numerical simulations we will assume the value $293 \mathrm{~K}$ as a reference temperature. With these numerical values from Tables 1 and 2 , the pesticide sorption coefficient $K_{\mathrm{d}}^{293}$, the apparent degradation rate $\mu_{293}$ and the Henry law constant $H_{293}$ are estimated by

Table 1. Average caracteristics of the Quartzous sand soil to the DAPESTE model

\begin{tabular}{lccccccc}
\hline $\begin{array}{l}\rho \\
\left(\mathrm{kg} \mathrm{m}^{-3}\right)\end{array}$ & $\theta$ & $\delta$ & $f_{\mathrm{cc}}$ & $\begin{array}{c}\overline{S S} \\
\left(\mathrm{~g} \mathrm{~m}^{-2}\right)\end{array}$ & $f_{\mathrm{cl}}$ & $\begin{array}{c}V \\
\left(\mathrm{~m} \mathrm{~d}^{-1}\right)\end{array}$ & $\begin{array}{c}\lambda \\
(\mathrm{m})\end{array}$ \\
\hline 1460 & 0.17 & 0.50 & 0.002 & 100 & 0.08 & 6.9 & $1.0 \times 10^{-5}$ \\
\hline
\end{tabular}

Table 2. Physico-chemical characteristics of the atrazine herbicide to the DAPESTE model

\begin{tabular}{lccccc}
\hline $\begin{array}{l}P_{\mathrm{w}} \\
\left(\mathrm{g} \mathrm{mol}^{-1}\right)\end{array}$ & $\begin{array}{c}V_{\mathrm{c}} \\
\left(\mathrm{cm}^{3} \mathrm{~mol}^{-1}\right)\end{array}$ & $\begin{array}{c}P_{\mathrm{v}}^{293} \\
(\mathrm{~Pa})\end{array}$ & $\begin{array}{c}S \\
\left(\mathrm{~g} \mathrm{~m}^{-3}\right)\end{array}$ & $\begin{array}{c}K_{\mathrm{oc}} \\
\left(\mathrm{mL} \mathrm{g}^{-1}\right)\end{array}$ & $\begin{array}{c}t_{1 / 2}^{293} \\
\left(\mathrm{~d}^{-1}\right)\end{array}$ \\
\hline 215.7 & 251 & $3.8 \times 10^{-5}$ & 33.0 & 100.0 & 60 \\
\hline
\end{tabular}


Equations (2), (9) and (12), respectively. Equations (5) and (7) are in $\left(\mathrm{cm}^{2} \mathrm{~s}^{-1}\right)$ and therefore, for the DAPESTE model the coefficient must be multiplied by 8.64 to be transformed to $\left(\mathrm{m}^{2} \mathrm{~d}^{-1}\right)$, the unit used in the DAPESTE model. The activation energy $E_{\mathrm{a}}=96 \mathrm{~kJ} \mathrm{~mol}^{-1}$ was calculated in the laboratory, with temperatures varying between 283 and $313 \mathrm{~K}$, by Andréa et al. (1997) in a sample of soil similar to the one given by Table 1 , and we have used this value in our numerical simulations. The heat of sorption $\Delta H_{\mathrm{a}}=-35.9 \mathrm{~kJ} \mathrm{~mol}^{-1}$ for atrazine was estimated by Equation (15) considering the soil specific surface area given in Table 1. This value indicates an endothermic sorption reaction. This $\Delta H_{\mathrm{a}}$ value is according to the experimental values determined by Fruhstorfer et al. (1993) for atrazine in montmorillonitic and kaolinitic clays, two soil constituents. The enthalpy of volatilization $\Delta H_{\mathrm{v}}=106 \mathrm{~kJ} \mathrm{~mol}^{-1}$ of atrazine was estimated by Equation (14). Equation (8) and the calculation procedures described by $\mathrm{Wu}$ and Nofzinger (1999) were used to determine the annual variation of daily average soil temperature at different depths of the soil described in Table 1. In our numerical simulations three distinct situations of minimal and maximal annual surface soil temperatures were used. In the first situation the soil surface temperature was maintained constant at $293 \mathrm{~K}$; in the second simulation scenario the soil surface temperature varied between the minimal 278 and the maximal of $298 \mathrm{~K}$; in the third simulation scenario the soil surface temperature varied from 288 to $308 \mathrm{~K}$.

The daily average temperatures of the entire soil profile of Table 2 were estimated for a time interval of 720 days. In all our simulations we assumed that the atrazine was applied to the soil on day 0 and that on this day the annual minimal temperature occurred. The dose applied in all the three simulations was of $0.4 \mathrm{~g} \mathrm{~m}^{-2}$. For the superficial top layer of incorporation we assumed the value $\varepsilon=0.05 \mathrm{~m}$. In all the numerical simulations the maximum depth $(z=+\infty)$ of the boundary condition, Equation (20), was of $l=2.5 \mathrm{~m}$. The longitudinal dispersion coefficient was $\lambda=1.0 \times 10^{-4} \mathrm{~m}$ in Equation (3) with $x=1.0$. These values were used in the model to simulate the concentrations of the herbicide atrazine in the solution of the soil. Using Equations (21) and (22), these concentrations determined the half-life of this herbicide in all the three situations of temperature chosen in our numerical simulations.

Therefore, fixing the depth of $1.0 \mathrm{~m}$ and considering the average values of the structural characteristics of the Quartzous sand soil given in Table 1 and the physical-chemical characteristics of the atrazine expressed in Table 2, the DAPESTE model estimated a concentration of $3.57 \times 10^{-4} \mathrm{~g} \mathrm{~m}^{-3}$ after 274 days from the application day and with soil surface temperature varying between 278 and $298 \mathrm{~K}$; the concentration $4.52 \times 10^{-5} \mathrm{~g} \mathrm{~m}^{-3}$ after 190 days from the application day and with soil surface temperature varying from 288 to $308 \mathrm{~K}$; and the concentration $5.96 \times 10^{-4} \mathrm{~g} \mathrm{~m}^{-3}$ after 240 days from the application day with soil constant temperature of $293 \mathrm{~K}$ (Figure 1). These results illustrate the importance of the soil temperature effect in the pesticide concentration in the same depth but in distinct soil temperatures. Figures 2-4 present the numerical results of the atrazine concentration evolution for various lengths of time and the profile for initial soil temperatures of $293 \mathrm{~K}$ varying between 278 and $298 \mathrm{~K}$ and between 288 and $308 \mathrm{~K}$. In these same figures, one can observe the effect of the initial soil temperature on the initial atrazine concentration given by the initial condition, Equation (17).

The curves of Figure 5 demonstrate the effect of different soil temperatures on the atrazine half-life in the soil. Similar curves and results were observed experimentally by Vischetti et al. (1997) for the herbicide rimsulforon in three different regimes of soil moisture and temperature. Such curves demonstrate that the hypothesis of first order degradation, frequently assumed in the studies of environmental behavior of pesticides or non-ionic organic chemical compounds, can be an erroneous decision. Alternatively a logistical hypothesis model could be more adequate, as observed by Veeh et al. (1996) for a kinetic degradation of 2,4-D in soils with temperature varying with depth. We can 


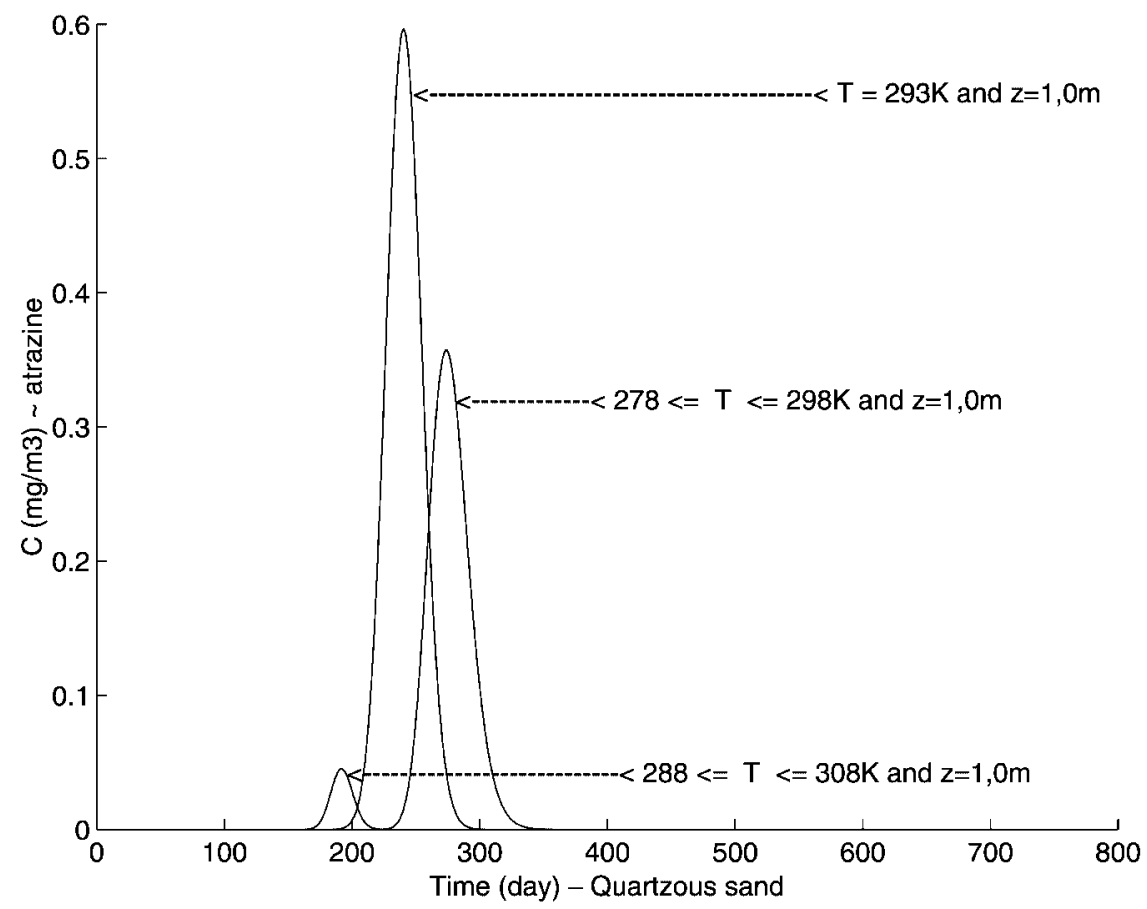

Figure 1. Simulation of the atrazine herbicide concentration by the DAPESTE model with $z=1.0 \mathrm{~m}$

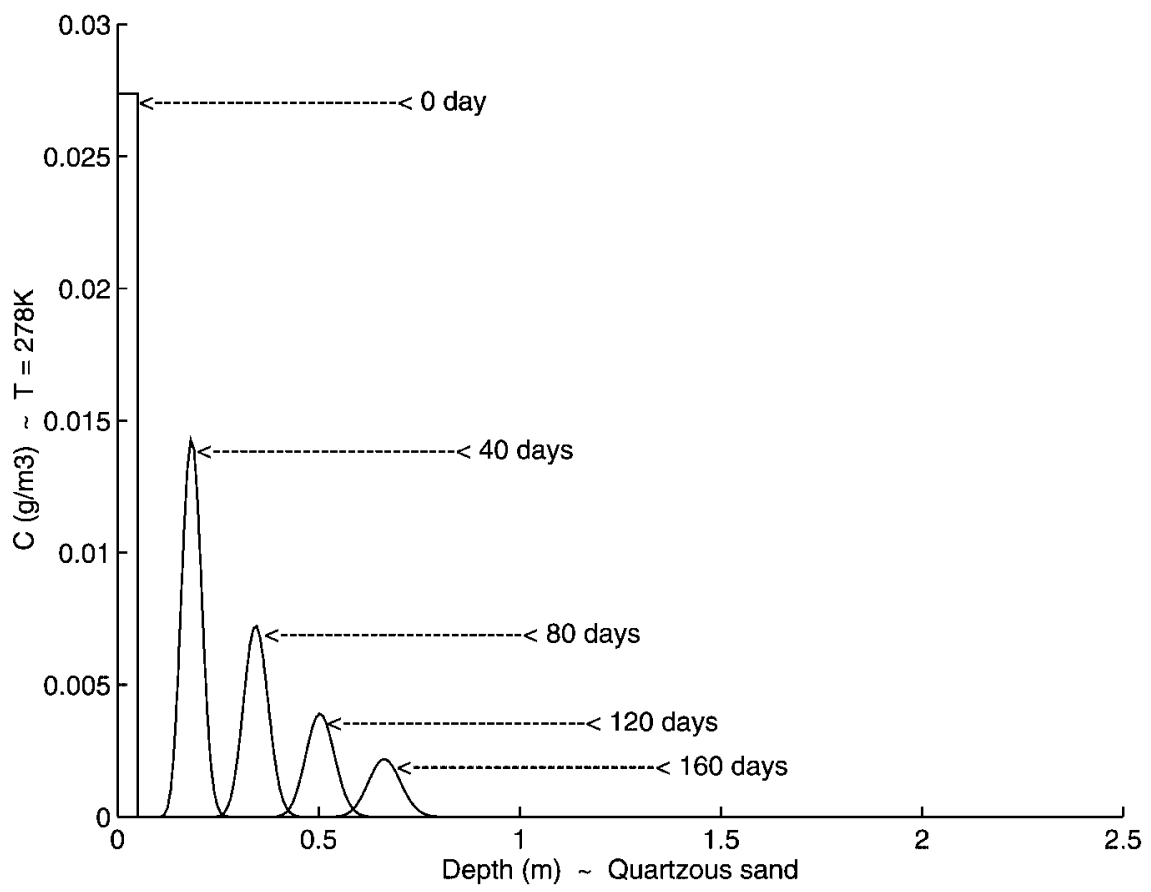

Figure 2. Simulation of the atrazine herbicide concentration by the DAPESTE model with $T(t, z)=293 \mathrm{~K}$ 


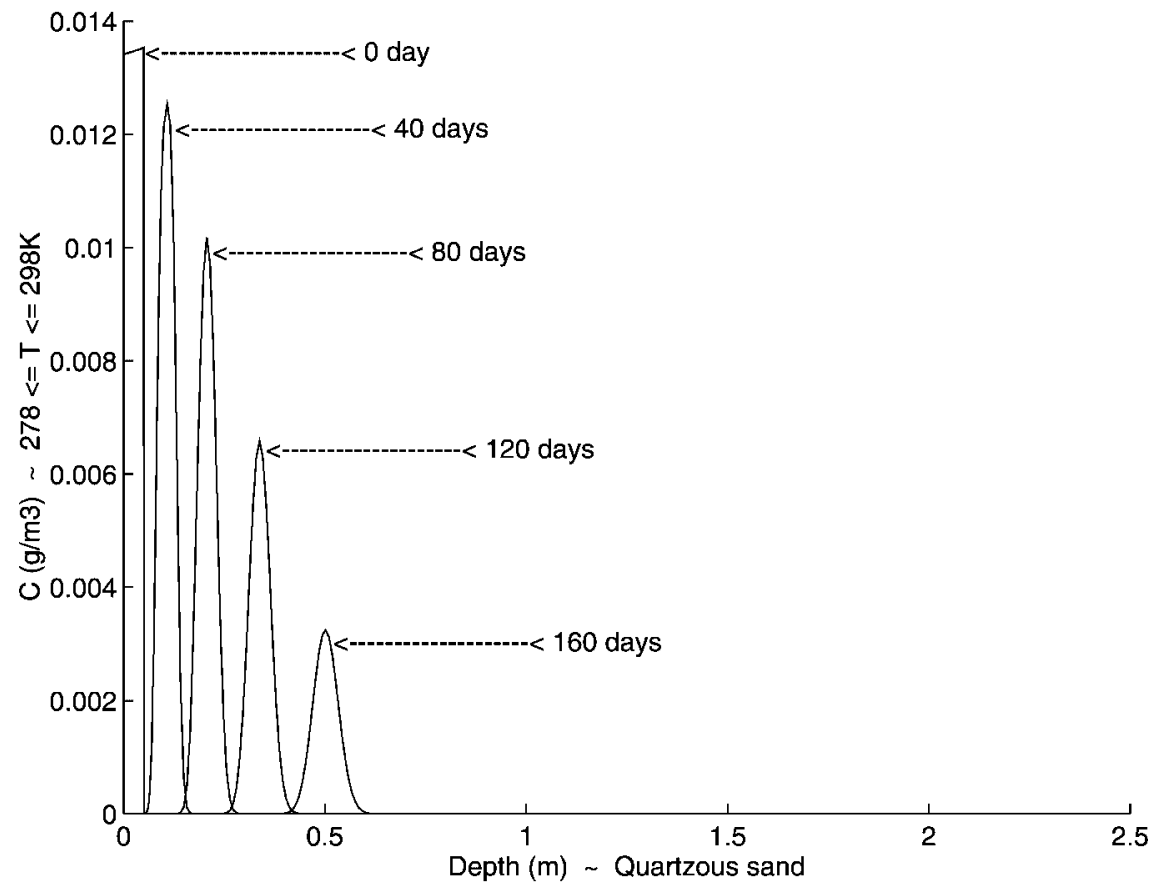

Figure 3. Simulation of the atrazine herbicide concentration by the DAPESTE model with $278 \mathrm{~K} \leq T(t, z) \leq 298 \mathrm{~K}$

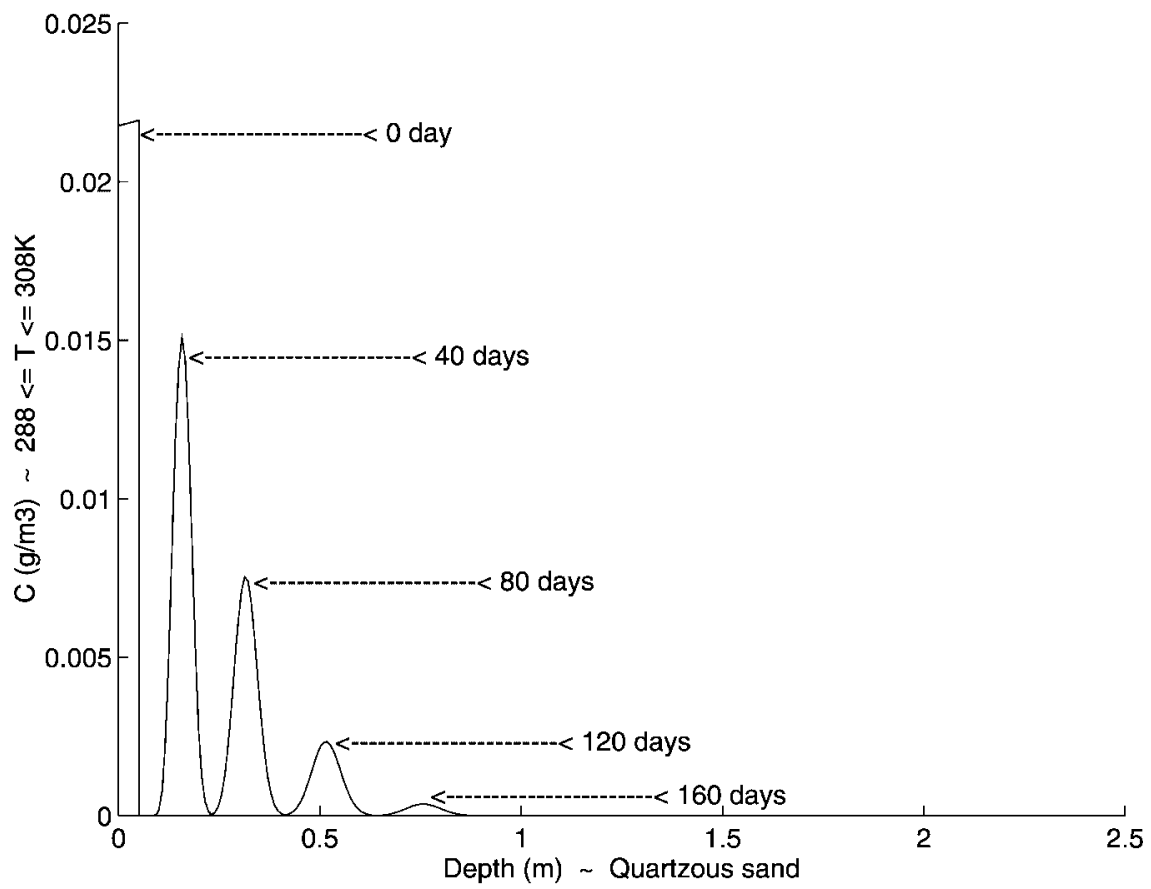

Figure 4. Simulation of the atrazine herbicide concentration by the DAPESTE model with $288 \mathrm{~K} \leq T(t, z) \leq 308 \mathrm{~K}$ 


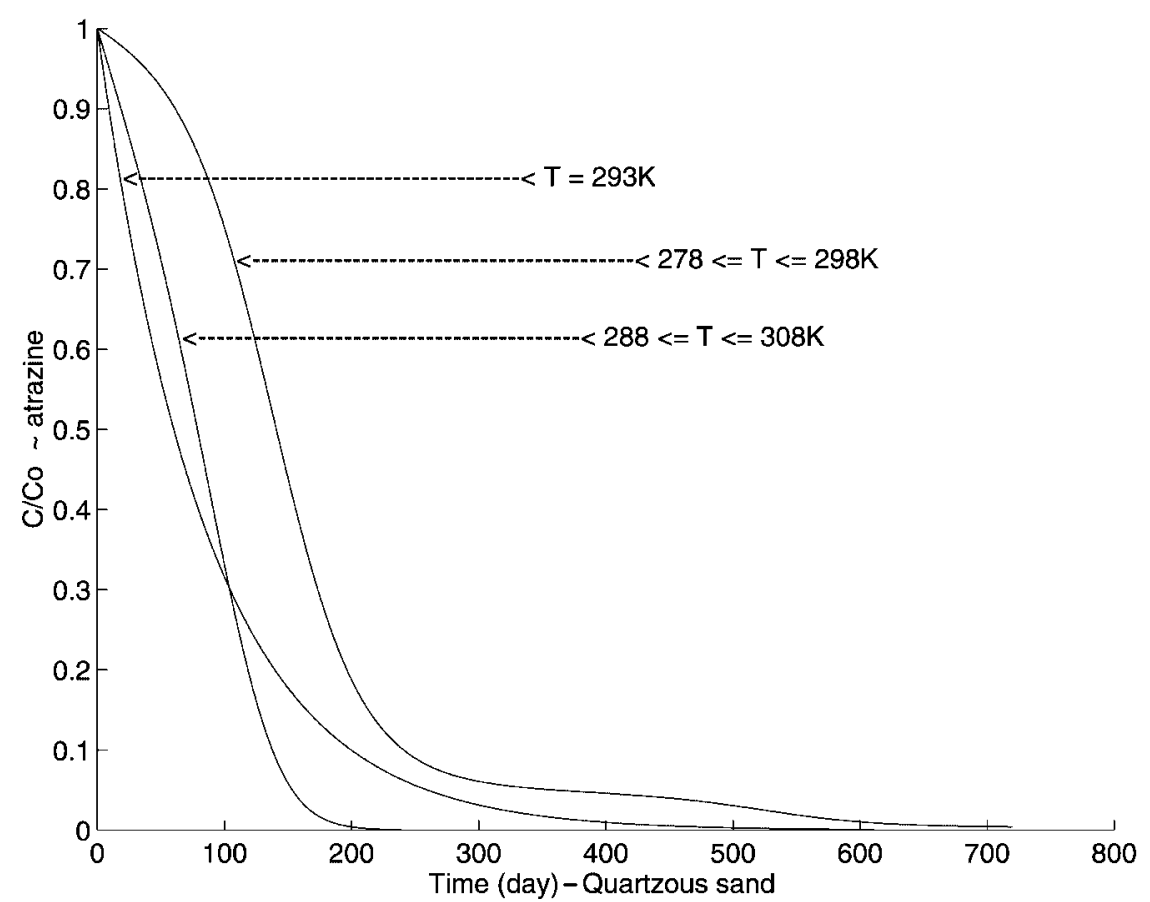

Figure 5. Simulation of the atrazine herbicide degradation by the DAPESTE model in the whole soil profile

observe from the degradation or relative concentration curves from Figure 5 the atrazine half-life in each situation of soil surface temperature chosen in our simulations. In fact, for $T=293 \mathrm{~K}$ we have an atrazine half-life $\hat{t}_{1 / 2}=60$ days, with $T$ varying between 278 and $298 \mathrm{~K}$ we have $\hat{t}_{1 / 2}=140$ days, and with $T$ varying between 288 and $308 \mathrm{~K}$ we have $\hat{t}_{1 / 2}=78$ days. We can state that atrazine is a hazardous chemical in sites where the soil temperature is low or very low, with top soil temperature less than $20^{\circ} \mathrm{C}$. In Figure 5, we conclude that this herbicide would become a very hazardous chemical compound to groundwater in sites where the temperature of the soil profile is relatively low or very low, with superficial soil temperature less than $20^{\circ} \mathrm{C}$.

According to Taylor and Spencer (1990), the two main environmental factors that affect the behavior of pesticides in the soil are the soil moisture and temperature, with moisture having a more significant relative weight than the soil temperature. However, Bromilow et al. (1999) observed that the soil moisture does not influence the degradation rate of five triazole fungicides and with their experiments identified an opposite relationship of dependence between the soil temperature and the degradation rate of these five fungicides.

\section{CONCLUSIONS}

The DAPESTE model has been presented. This model considers the effect of the soil temperature on the degradation rate, Henry's constant, sorption coefficient, and gaseous and aqueous diffusivity of the pesticide in the soil matrix. The equation is adopted for the soil temperature profile to describe the 
annual variations of daily average soil temperature at different depths. The thermodynamic parameters of the model with enthalpy of volatilization, and heat of sorption and activation energy, are not frequently encountered in the literature or in databases on pesticides, and this difficulty could harden the use of the models presented in this article. However, when these values are known experimentally or determined we can make valuable estimations on the behavior of pesticides in the soil. The governing equation presented supposes that the velocity of pore water and the hydraulic properties of the soil are constant. The adaptation of the DAPESTE model for saturated or partly saturated soils with a variable velocity pore water is possible. The utilization of numerical methods of the finite elements type was made necessary for the periodical characteristic of the parameters involved in the conception of the governing equation of the DAPESTE model. The simulations presented indicate the importance of the soil temperature in the leaching of pesticides, mainly because of its significant influence on the pesticide degradation rate and pesticide sorption coefficient. For some volatile compounds such as the herbicide trifluraline and molinate the effect of the soil temperature on the partition water-air coefficient of the Henry law is also significant. Considering only the effect of the temperature on the retard factor parameters and on the degradation rate of the pesticide in the soil, we can observe how important the soil temperature is in the study of the environmental behavior of pesticides and nonionic organic compounds, as much for its agronomic efficiency as for the protection of the quality of surface and groundwater. Our model presents a numerical solution by finite elements to the dispersion-advection equation applied to transport of pesticides based on the soil temperature effect, that is in FORTRAN (1997) 90 code under the Windows 98 menu bar, and it can be run in sequential form. In a future work, we will study mathematical details of the numerical methods and algorithms used in the development of the simulation model presented in this article.

\section{REFERENCES}

Anderson MP. 1979. Using models to simulate the movement of contaminants through groundwater flow systems. Crit. Rev. Environ. Control 9: 97-156.

Andréa MM, Matallo MB, Tomita RY, Luchini LC. 1997. Effect of temperature on dissipation of [14C]-atrazine in a Brazilian soil. Pesq. Agropec. Bras. 32(1): 95-100.

Bacci E. 1994. Ecotoxicology of Organic Contaminants. Lewis Publishers: Boca Raton, FL.

Bear J. 1972. Dynamics of Fluids in Porous Media. Elsevier: New York.

Bigger JW, Nielson DR. 1976. Probability, Statistics, and Decision for Civil Engineers. McGraw Hill Book Company.

Bird RB, Stewart WE, Lightfoot EN. 1960. Transport Phenomena. Wiley: New York.

Boesten JJTI. 2000. From laboratory to field: uses and limitations of pesticide behaviour models for the soil/plant system. Weed Research 40: 123-138.

Bromilow RH, Evans AA, Nicholls PH. 1999. Factors affecting degradation rates of five triazole fungicides in two soil types: 1. Laboratory incubations. Pesticides Science 55: 1129-1134.

Campbell GS. 1985. Soil Physics with Basic: Transport Models for Soil-Plant Systems. Elsevier: Amsterdam.

Chiou CT, Peters LJ, Freed VH. 1979. A physical concept of soil-water equilibria for nonionic organic compounds. Science 206: 831-832.

Currie JA. 1965. Diffusion within the soil microstructure-a structural parameter for Soil. J. Soil Sci. 16: $279-289$.

EPA. 1990. US Environmental Protection Agency. National Survey of Pesticides in Drinking Water Wells. Phase I Report. Washington, DC.

Esser HD, Dupuis G, Ebert E, Marco G, Vogel C. 1975. s-Triazines. In Herbicides, Chemistry, Degradation, and Mode of Action, Kearney PC, Kaufman DA (eds). Marcel Dekker: New York; 129-208.

Frank R, Sirons GJ. 1985. Dissipation of atrazine residues from soils. Bull. Environ. Contam. Toxicol. 34: 541-548.

Freijer JI, Veling EJM, Hassanizadeh SM. 1998. Analytical solutions of the convection-dispersion equation applied to transport of pesticides in soil columns. Environmental Modelling \& Software 13: 139-149.

Fruhstorfer P, Schneider RJ, Weil L, Niessner R. 1993. Factors influencing the adsorption of atrazine on montmorillonitic and kaolinitic clays. The Science of the Total Environment 138: 317-328.

Goss KU, Schwarzenbach RP. 1999. Empirical prediction of heats of vaporization and heats of adsorption of organic compounds. Environ. Sci. Technol. 33: 3390-3393. 
Hance RJ. 1987. Herbicide behaviour in the soil, with particular reference to the potential for groundwater contamination. In Herbicides, Hutson DH, Roberts TR (eds). John Wiley \& Sons: New York; 223-247.

He Y, Yediler A, Sun T, Kettrup A. 1995. Adsorption of fluoranthene on soil and lava: affects of the organic carbon contents of adsorbents and temperature Chemosphere 30(1): 141-150.

Hillel DGM. 1982. Introduction to Soil Physics. Academic Press: San Diego, CA.

Hornsby AG, Don Wauchope R, Herner AE. 1996. Pesticide Properties in the Environment. Springer-Verlag: New York.

Howard PH. 1989. Handbook of Environmental Fate and Exposure Data for Organic Chemicals: Pesticides. Lewis Publishers: Chelsea, MI.

Johnson C. 1987. Numerical Solution of Partial Differential Equations by the Finite Element Methods. Cambridge University Press: New York.

Jury WA, Gardner WR, Gardner WH. 1991. Soil Physics. John Wiley \& Sons Inc.: New York.

Jury WA, Russo D, Streile G, El Abd H. 1990. Evaluation of volatilization by organic chemicals residing below the soil surface. Water Resource. Res. 26: 13-20.

Jury WA, Spencer WF, Farmer WJ. 1983. Behavior assessment model for trace organic in soil: I. Model description. J. Environ. Qual. 12(4): 558-564.

Kavanaugh MC, Trussel RR. 1980. Design of aeration towers to strip volatile contaminants from drink water. J. Am. Water Works Assoc. 72(12): 684-692.

Keen RE, Spain JD. 1992. Computer Simulation in Biology: A Basic Introduction. Wiley-Liss: New York.

Klotz D, Seiler KP, Moser H, Neumaier F. 1980. Dispersivity and velocity relationship from laboratory and field experiments. J. of Hydrology 45: 169-184.

Lahey Computer Systems, Inc. 1997. Fortran 90 User's Guide and Lahey/INTERACTER Starter Kit.

Lindstrom FT, Boersma L. 1971. A theory on the mass transport of previously distributed chemicals in a water saturated porous medium. Soil Science 111: 192-199.

Lyman WJ, Reehl WF, Rosenblatt DH. 1982. Handbook of Chemical Property Estimation Methods. American Chemical Society: Washington, DC.

Mackay D, Paterson S, Schroeder WH. 1986. Model describing the rates of transfer processes of organic chemicals between atmosphere and water. Environ. Sci. Technol. 20: 810-816.

Marshall TJ, Holmes JW. 1988. Soil Physics. Cambridge University Press: New York.

Millington RJ. 1959. Gas diffusion in porous media. Science 130: 100-102.

Millington RJ, Quirk JP. 1961. Permeability of porous solids. Trans. Faraday Soc. 57: 1200-1207.

Padilla F, Lafrance P, Robert C, Villeneuve JP. 1988. Modeling the transport and the fate of pesticides in the unsaturated zone considering temperature effects. Ecological Modelling 44: 73-88.

Rappaz J, Picasso M. 1998. Introduction à l'Analyse Numérique. Presses Polytechniques et Universitaires Romandes.

Reichman R, Mahrer Y, Wallach R. 2000a. A combined soil-atmosphere model for evaluating the fate of surface-applied pesticide. 1. Model development and verification. Environ. Sci. Technol. 34: 1313-1320.

Reichman R, Mahrer Y, Wallach R. 2000b. A combined soil-atmosphere model for evaluating the fate of surface-applied pesticide. 2. The effect of varying environmental conditions. Environ. Sci. Technol. 34: 1313-1320.

Sagebiel JC, Seiber JN, Woodrow JE. 1992. Comparison of headspace and gas-stripping methods for determining the Henry's law constant $(\mathrm{H})$ for organic compounds of low to intermediate H. Chemosphere 25(12): 1763-1768.

Staudinger J, Roberts PV. 1996. A critical review of Henry's law constants for environmental applications. In Critical Reviews in Environmental Science and Technology (Vol. 26), Logan TJ (ed.). CRC Press; 205-297.

Sun NZ. 1995. Mathematical Modeling of Groundwater Pollution. Springer: New York.

Szecsody JE, Bales RC. 1991. Temperature effects on chlorinated-benzene sorption to hydrophobic surfaces. Chemosphere 22(12): 1141-1151.

Taylor AW, Spencer WF. 1990. Volatilization and vapor trnasport processes. In Pesticides in the Soil Environment: Processes, Impacts, and Modeling, Cheng HH (ed.). Soil Science Society of America Book Series: Wisconsin; 214-269.

Toride N, Leij FJ, Van Genuchten MTh. 1993. Flux-averaged concentrations for transport in soils having nonuniform initial solute distributions. Soil Sci. Soc. Am. J. 57: 1406-1409.

Trouton R. 1884. IV. On molecular latent heat. Phil. Mag. 18: 54-57.

Veeh RH, Inskeep WP, Camper AK. 1996. Soil depth and temperature effects on microbial degradation of 2,4-D. J. Environ. Qual. 25: 5-12.

Vighi M, Di Guardo A. 1995. Predictive approaches for the evaluation of pesticide exposure. In Pesticide Risk in Groundwater, Vighi M, Funari E (eds). CRC Press, Inc.: Lewis Publishers, Boca Raton; 73-100.

Vischetti C, Perucci P, Scarponi L. 1997. Rimsulfuron in soil: effect of persistence on growth and activity of microbial biomass at varying environmental conditions. Biogeochemistry 39: 165-176.

Wagenet RJ, Rao PSC. 1990. Modeling pesticide fate in soils. In Pesticides in the Soil Environment: Processes, Impacts, and Modeling, Cheng HH (ed.). Soil Science Society of America Book Series: Wisconsin; 351-399.

Walker A. 1987. Evaluation of a simulation model for prediction of herbicide movement and persistence in soil. Weed Research 27: $143-152$.

Wang YS. 1999. Environmental impact of herbicide use in the subtropics. Food Science and Agricultural Chemistry 1(3): $165-179$. 
Wauchope RD, Buttler TM, Hornsby AG, Augustijn-Beckers PWM, Burt JP. 1992. Pesticide properties database for environmental decision making. Rev. Environ. Contam. Toxicol. 123: 1-157.

Weber WJ, Jr, DiGiano AF. 1995. Process Dynamics in Environmental Systems. Environmental Science and Technology: a Wiley-Interscience Series of Texts and Monographs: New York.

Wu J, Nofzinger DL. 1999. Incorporating temperature effects on pesticide degradation into a management model. J. Environ. Qual. 28: 92-100. 